\title{
The Effect of Inquiry-Based Teaching-Learning Sequence in Ameliorating Alternative Conceptions and Conceptual Difficulties of Conservation of Mechanical Energy
}

\author{
Rankhumise Mmushetji Petrus
}

Raphoto M .S

\author{
Central University of Technology), Private bag x20539, Bloemfontein, 9300
}

Email:mprankhumise@cut.ac.za

Doi:10.5901/mjss.2014.v5n15p366

\section{Abstract}

The understanding of the scientific meaning of the concept of energy and the principle of the conservation of mechanical energy is affected by various connotations and meanings that the concept and principle have in everyday language use. Young children develop and formulate their own conceptual meanings and understanding of the concepts that often differ from the scientific meanings. These preconceived ideas are termed alternative conceptions of the learners. Learners associate the concept of energy with living and moving objects, in other words, the difficulties experienced by learners in comprehending the scientific concept of energy and its conservation are embedded in their anthropocentric and anthropomorphic views. Focusing on the nature and origins of these alternative conceptions held by learners, a literature study of contemporary constructivist teaching and learning strategies was conducted. The theoretical investigations led to an empirical study. A quantitative action research methodology was undertaken. Firstly, a questionnaire was designed and administered to grade 10 learners to diagnose their alternative conceptions about the concept of energy and the principle of conservation of energy. The results of the questionnaire were analyzed to determine the nature of the alternative conceptions held by the learners. Secondly, an intervention program was designed. During the intervention various factors that might contribute to learners' conceptualization of the concept of energy were utilized. Contemporary teaching-learning approaches and strategies, which are constructivist in nature, were used. Inquiry teaching was implemented through the $5 E$ instructional model. The teaching and learning experiences were contextualized, i.e., they were designed using situations and experiences that were familiar to the learners. Thirdly, the success of the intervention to accomplish conceptual change was assessed. The analysis of the results of the empirical study shows a significant improvement of the learners' understanding of energy and its conservation. This was reflected in the calculated normalized learning gain of $65 \%$. The results show the importance for teachers to continuously do action research on various aspects of the educational environment like learners' alternative conceptions, contemporary teaching-learning strategies and contextual factors that might influence effective teaching and learning

Keywords: Alternative conceptions, conceptual change, instructional model, normalized gains, mechanical energy

\section{Introduction}

The word 'energy' is often used fairly loosely in and out of the science classroom. It is a very difficult scientific concept to define satisfactorily (Hewitt, 2002:p104: Mann and Treagust, 2013:p145). Energy is a theory-loaded concept that can be best understood within the framework of its related concepts, laws and supportive theories (Sexl, 1981:pp293-294, Mann and Treagust, 2013:p144). In everyday life, the idea of obtaining energy from fuels or food is familiar and it is a general idea to consider fuels (including food) as stores of usable energy from which proportions of energy can be withdrawn (Friedl, 1991:p283). Energy taken from fuels (e.g. petrol for cars) enables useful tasks to be performed (e.g. transport). These everyday-life ideas should be expanded or refined towards an understanding of the scientific concepts (Lemmer\&Lemmer, 2008:p15; Trumper, 1990:210).

Learners often regard energy as anthropomorphic and anthropocentric (Watt, 1983:p214, Mann et al, 2013:pp145146). Children tend to consider non-living objects as being alive and energy as the property of only living and moving objects.

Research studies show that even if learners receive formal instruction on concepts such as energy they still harbour, adhere to and hold firmly onto their alternative conceptions (Rankhumise \&Lemmer, 2008:p596). This could have been brought about by the use of traditional teaching and learning strategies which are teacher centred and whereby the learner is the passive recipient of information and knowledge. It is difficult for a teacher to change learners' alternative conceptions about any particular concept in formal teaching. For better understanding of scientifically correct 
concepts, it is essential that a combination of a variety of constructivist teaching and learning approaches are used (Trumper, 1991:p6; Trowbridge,Bybee \&Powell, 2000:p224; Scott, Asoko \& Driver 1991:p7).

The problem attended to in this study is how to treat and handle learners' alternative conceptions relating to the principle of conservation of mechanical energy. The study investigates the effectiveness of an inquiry teaching-learning sequence aimed to remedy alternative conceptions that learners have relating to mechanical energy and the conservation thereof. The focus is on Grade 10 learners, because Grade 10 learners are introduced to the Further Education and Training (FET) level in which the concepts are formalized. Conceptual understandings of these concepts are vital before formalization (Lemmer \& Lemmer, 2005:pp212-213).

The teaching-learning sequence compiled and implemented in this study follows the design principles of progression and integration in the implementation of the OBE curriculum (Nieuwoudt\& Beckley, 2008:pp324-328). The progression principle enables learners to gradually develop more complex, deeper and broader knowledge, skills and understanding. The integration principle requires learners to apply their knowledge and skills in other contexts. In this study learners were required to integrate their classroom knowledge with everyday experiences.

\section{Literature Review}

The law of conservation of energy is often confused with the everyday language use of the words "law" and "conservation" (Boyes\&Stanisstreet, 1990:p51; Wesi, 2003:p248). For example, the word "law" is understood by children from everyday language use as a prohibiting statement of which, when contravened, the results are negative. In science the word is understood and interpreted as either a formula or as behaviour of natural phenomena within certain confines and conditions

Conservation of energy is thought of or talked about as the wise and useful use of energy resources, i.e., to use energy more efficiently and not to waste it. Scientifically, conservation of energy involves energy changes into different forms. Although some forms like heat, sound and light may be less useful, the total amount of energy remains constant (Kotz\&Treichel, 1996:p162; Boyes\&Stanistreet, 1990:p51; Wesi, 2003:p248).

In mechanics, the most common alternative conceptions held by learners regarding the concept of energy and energy conservation are anthropocentric and anthropomorphic in nature (Trumper, 1991). Energy is mainly associated with moving and living things. For example, learners will agree that a person walking up-hill has energy obtained from food (fuel) as much as the tractor pulling a trailer up-hill has energy obtained from the fuel it uses. But they will think that a tractor that is stationary on an inclined plane does not possess energy because it is neither living nor moving. The following alternative conceptions relating to the concept of mechanical energy may be displayed by both learners and teachers (Watt, 1983:pp214-216; Wesi, 2003:p260; Rankhumise and Lemmer, 2008:596):

Interchangeable terms and the relation between energy and other concepts.

> The terms "energy", "force" and "power" are used interchangeably and in some instances might mean the same thing.

$>$ The word "work" is synonymous with labour from everyday language use, experiences and observations.

$>$ Energy conservation means wise use or taking good care of energy.

$>$ The statement "law of conservation of energy" is confused with statutory laws, which have prohibiting statements.

Energy is associated with living things and motion.

$>$ An object at rest has no energy.

$>$ A non-living object has no energy.

Energy expenditure (energy is used up).

$>$ Objects use up energy; for example, a car that has run out of petrol has used up its energy.

$>$ A person who is tired after hard work has used up his or her energy.

Energy is a fuel

$>$ Energy is considered as material that can be used for essential tasks or something that can propel other objects, e.g. fuels (like petrol, paraffin, diesel, etc) and electricity.

Problems relating to the concept of potential energy.

$>$ Learners think that objects at rest cannot have any energy.

$>$ Gravitational potential energy is perceived to only depend on the height of an object above a chosen reference level.

Problems relating to the conservation of mechanical energy.

$>$ According to everyday experiences, we can "run out of energy". 
$>$ Energy is lost in energy transformations.

$>$ Different amounts of energy are used when pushing or pulling a cart up a hill of the same height.

The problem attended to in this study is how to treat and handle learners' alternative conceptions relating to the principle of conservation of mechanical energy. The study investigates the effectiveness of an inquiry teaching-learning sequence aimed to remedy alternative conceptions that learners have relating to mechanical energy and the conservation thereof. The focus is on Grade 10 learners, because Grade 10 learners are introduced to the Further Education and Training (FET) level in which the concepts are formalized. Conceptual understandings of these concepts are vital before formalization (Lemmer\&Lemmer, 2005:p213).

According to Meheut and Psillos (2004:p515) and Meltzer (2002:pp1259-1261), it is important to find out about and recognize alternative conceptions that learners bring to science classes prior to formal instruction. This follows from the constructivist theory of learning. The essence or interest of teaching and learning science emphasis improved learners' understanding of scientific knowledge and their participation in science related fields once they leave formal schooling (Roth \&McGinn, 1998:p213; Ogunniyi\&Taale, 2004:p77).

The constructivist teaching-learning theory suggests that the teacher has to play an important role to facilitate learners' conceptual change (Scott,Asoko,\& Driver,1991:pp5-I0; Scholtz\&Amosun, 2004:pp41-42). The teacher has to do the following (Department of Education, 2003):

$>$ Act as a diagnostician, i.e., to diagnose learners' alternative conceptions prior to formal presentation and also elicit them.

$>$ Act as a learning mediator, i.e., be able to recognize learners' individual needs and how they learn.

Develop strategies that will enable him/her to deal with these alternative conceptions held by learners.

$>$ Be a scholar, researcher and lifelong learner by keeping up to date with new developments in the discipline and profession.

$>$ Develop evaluation techniques, which take into account how learners solve problems and also to what extent they grasp and understand scientific concepts.

The inquiry teaching-learning strategy is not only confined within the limits of science teaching and learning. Inquiry is used in other areas of human learning such as social problems, politics, mathematics, literature, history and others. The inquiry teaching and learning strategy depicts the process through which human beings seek information and understanding through processes such as observations, experiments and experiences, which result in empirical evidence about the natural world. When learners study science using inquiry they employ many different skills (e.g. physical and intellectual skills). Through inquiry the inquisitive nature of the learners is nurtured and they (learners) become justified and interested in what they are doing. Once interested, the learners acquire cognitive skills and knowledge, and an increase in positive attitudes towards science learning is developed (Gunter Estes,\&Schawb, 1991:p43; Redish, 2003:pp156-161; Trowbridge Bybee,\& Powell, 2000:p175; Kask\&Rannikmae, 2006:p12; Bricker,2005:p15, McBride,Bhatti,Hannan2004:p434).While conceptual change is difficult, a number of approaches have shown promise for promoting conceptual learning relative to traditional instruction.Most of those approaches are active engagement methods and many are inquiry-based (Prince \& Margot,2012:p1).Prince and Felder(2007:p30) provide extensive evidence that a variety of inquiry-based instructional approaches are effective for promoting conceptual understanding as well as additional educational outcomes

Considering the new curriculum (Department of Education, 2003), teaching the energy concept and the principle of conservation fits well in the general education and training band (GET). The band starts from grade four and proceeds to grade nine (grade 4-9). In this band, the core knowledge of the concept of energy and energy changes are found in the knowledge area called Energy transfers and systems (Department of Education, 2002:p66). In this knowledge area learners are introduced to various sources of energy and benefits of different energy forms that are required to meet and cater for our daily needs and services (qualitative aspect of energy). The concept of energy is thus gradually developed in this band.

Given the level of learners' development, this is the band in which learners' alternative conceptions are prevalent. Therefore, this is the band that provides a convenient platform to teach learners conceptual change (Zain\&Sulaiman, 1998:p415). The strategies and approaches to be used in this band (GET) must be constructive in the sense that learners must be active and purposeful during the learning process. Learners must also be actively involved in bringing prior knowledge to bear in order to construct meanings in new situations (Trumper, 1991:pp2-3).

In the further education and training (FET) band that ranges from grade ten to twelve (grade 10-12), learners may still have alternative conceptions about the concept of energy (Rankhumise \&Lemmer, 2008:p598). The concept of energy under the knowledge area Mechanics is treated and defined more formally because of its quantitative nature. 


\section{Research Design and Methodology}

\subsection{Research methodology.}

An action research methodology is used. Through action research opportunities are created where systematic reflections on classroom activities causing effective and efficient changes that are beneficial to both teaching and learning, can be made (Leedy\&Ormrod, 2001:p430; Feldman \& Minstrel, 2000:p431). As explicitly defined by Leedy and Ormrod (2001:p432), action research is a way of taking a systematic, close and critical look at the way in which one teaches, with a view of changing it so that the classroom experiences become more meaningful for all those involved. Reflecting critically on what takes place in one's classroom is important to learners' learning as well as to advance the knowledge of the teaching and learning of science (Leedy\&Ormrod, 2001:p430; Feldman \&Minstrell, 2000:p431).

Action research is a contextualised form of research (it is done by the teacher on his or her own practice in his or her own classroom) and it is developmental in nature. I.e., a teacher is kept abreast and up to date with new developments in his or her discipline and profession, as is required by the Department of Education (Department of Education, 2003:p5; Feldman \&Minstrell, 2000:p432).

The purpose of choosing action research methodology for this study is to seek ways and means of improving teaching and learning as well as to have a better comprehension of the educational environment.

\subsubsection{Implementation of action research}

The research method is divided into three stages namely action planning, action taking and the evaluating stage. The method (action research) of this study allows for modification of the intended intervention after analysing, evaluating and reflecting upon the results of the pre-test. The stages of the research design are outlined as follows:

$>$ Action planning - A pre-test questionnaire was prepared and administered to diagnose the alternative conceptions held by the learners. The alternative conceptions that have to be attended to in the intervention follows from the learners' responses.

$>$ Action taking (intervention) - Inquiry orientated lessons were designed and presented to learners in order to remedy alternative conceptions held or to build on already existing knowledge. Six lessons of forty-five minutes each were designed. The content of the lessons is contextualised, i.e., the activities are drawn up in such a way as to engage learners to use their daily experiences and observations while responding to the situations presented. Apart from participating in the lessons, the learners carried out a research project. To do the project, the learners were divided into six groups of about six learners per group. Each group was requested to record and report instances and

situations where they had observed the application of mechanical energy transfer and its conservation from their immediate environment.

$>$ Evaluating stage - The same questionnaire used in the pre-test was again used for the post-test. The statistical data of the pre- and post-tests is compared, analysed, interpreted and documented. Learning gains are calculated from these results. Conclusions and recommendations follow from the results.

\subsubsection{Composition and assessment of the questionnaire/ intervention.}

The introductory portion of the questionnaire consists of the biographical information and the body portion consisted of two parts namely Part 1 and Part 2of the questionnaire is a project.

\subsubsection{Study Population}

The study focuses on a group of thirty-seven grade 10-science learners (nineteen boys and eighteen girls). The learners were enrolled at one of the high schools in South Africa. Grade 10 learners were used to ensure that they have the scientifically correct conceptual understanding of the qualitative conceptions of energy and its conservation before it is introduced quantitatively in the FET band.

\subsubsection{Research Instrument}

A questionnaire was designed and used as both a pre- and post-test. The questionnaire developed for the study is based 
on learners' daily experiences and observations.

\subsubsection{The biographical information.}

In the biographical portion learners are requested to fill in the following information: Their names, gender, age and the date. The names of the learners and the dates of the administration of the questionnaire are used to determine the following:

$>$ Name: Names are used to determine the conceptual change and learning gains accomplished and whether constructive learning of individual members of the target group has taken place due to the intervention.

Date: Dates are used to determine the maturation period of the pre-test and post-test results of the questionnaire. The maturation period for the pre-test and post-test results is one month. I.e., the same questionnaire that was used in the pre-test was administered a month after the intervention to the target group.

\subsubsection{Part 1of the questionnaire.}

Part 1 of the questionnaire consists of seven items with statements or questions, which require learners to respond by referring to and inferring from the pictorial scenario presented. The questions are conceptual in nature and focus on the two major kinds of energy namely kinetic and potential energy. The questions also aim to find out if learners can apply the concepts of energy and the principle of conservation of mechanical energy in everyday life situations and/or contexts.

Classification of questions in Part 1 of the questionnaire.

Questions 1.1.Does the stone inside the catapult have energy? 1.2The stone is fired towards the target (tin). Does the fired stone have energy while it is in the air,1.4.Does the target (tin) posses energy before it is hit?and 1.7.The target is hit and falls down. While falling does the target have energy? in Part 1 of the questionnaire focus on the identification of energy forms illustrated by the scenario presented. Questions 1.3,Has energy been created by the catapult? 1.5. Does the stone do work on the tin when it hits it?and 1.7The target is hit and falls down. While falling does the target have energy?address the concept of energy transfer taking place in the system. Lastly, questions 1.3. Has energy been created by the catapult?and 1.6ls energy lost when the stone hits the tin? of thequestionnaire focus on the principle of conservation of mechanical energy in a system. Key words used for question 1.3 and 1.6 are created and lost respectively.

The reason for using the same questionnaire in both the pre- and post-tests is to determine the effectiveness of the intervention to accomplish conceptual change of the alternative conceptions revealed in the pre-test. The questionnaire should be valid and reliable. Validity of the items or questions in the survey means that the items or questions of the questionnaire should measure what is supposed to be measured. Reliability means the results should be consistent and reproducible as opposed to repeatability (Kelly \&Lesh, 2000:pp28-29; Redish, 2003:pp96-97).

The content validity (the survey item should measure what it claims to measure) of the questionnaire was checked and judged by an expert in science education and fellow postgraduate students. After thorough checking and rechecking some suggestions were made to change some questions, questions statements, items, and item statements and the questionnaire was considered valid.

The reliability (reproducible results, not repeatable) of the questionnaire was determined by administering the same questionnaire to the target group a month later. The results of the pre-and post-tests were checked and evaluated to determine possible gains achieved (Redish, 2003:pp96-98)

\subsubsection{Intervention}

Six teaching and learning experiences were designed in accordance with the National Curriculum Statement policy for grade 10 to 12 physical sciences (Department of Education, 2003:pp9-11). Attention was paid to the progression of the learners' knowledge. The teaching-learning experiences were contextualised, i.e., familiar and observable phenomena from the learners' environment were used. The main teaching-learning approach used was an inquiry strategy integrated with direct instruction and lecture-based models. The integrated teaching-learning approach as discussed in paragraph 3.4 is also highlighted in the learning outcomes of physical sciences in the policy document (Department of Education, 2003:13-14).

Each teaching-learning experience consisted of three stages, namely:

$>$ Stage 1: Identification of two major forms of energy.

$>$ Stage 2: Discussion of energy changes that take place in the system and the principle of conservation of 
mechanical energy.

$>$ Stage 3: Application of the energy transformation concept and the principle of conservation of mechanical energy.

The first stage (lessons 1 and 2) was designed to enable learners to distinguish energy forms (potential and kinetic energy) from types of energy (like solar, chemical, radiation, etc.) and also to identify energy forms from types in a system (e.g. heat as the average kinetic energy of particles).

The concept of energy transformation and the principle of conservation of mechanical energy were introduced in the second stage (lessons 3 and 4). The purpose of these lessons was to create conflicting situations where learners would be able to recognize their limitations in explaining the concept of energy transformation and the principle of conservation of mechanical energy and would realize that their intuitions may be opposed to the scientific explanation. Learners were also expected to be able to quote and recognize the application of the principle of conservation of mechanical energy.

The final stage (lessons 5 and 6 ) was designed to help learners to be able to apply and recognize the application of energy transformation and the principle of conservation of mechanical energy in another context. In this stage learners were requested to do a case study in their environment and compile a report on situations where they had encountered or observed energy transformation and the principle of conservation of mechanical energy in application (for example, in the community a tractor with a malfunctioning self-starter is usually placed on a sloping surface in order to start).

Others were asked to design (project) models where the principle could be applied (for example, some gates in the community can close automatically when opened; attaching a spring or rubber strand at one end of the gates does this).

Lesson plans and classroom activities.

Lesson 1 - definition of potential and kinetic energy.

In the developmental stage learners were requested to find definitions of the terms kinetic and potential energy from their textbooks. The presentation stage entailed active and interactive participation to identify energy forms in the system presented. Learners were always reminded to pay much attention to definitions given when identifying energy forms in the system. Teaching-learning materials used to facilitate the lesson were a soccer ball, a brick, and a shot put ball. During group work and reflection on the activities carried out, discussions and arguments between learners and learners and the teacher occurred freely. Teaching-learning activities designed were as follows:

Activity 1.1.Learners had to roll the balls and refer to the definitions of the terms to identify the energy form possessed by a rolling ball.

Activity 1.2.Learners had to raise and hold steady a shot put ball with an outstretched arm through different heights (knee level, waist height, shoulder height). In this activity learners had to identify the energy form possessed by the ball through these heights and then note and record the height where the ball becomes difficult to balance

Activity 1.3.The masses of the three different objects (soccer ball, brick and shot put ball) were measured and recorded. The raising act was repeated for the three objects so that observations and comparisons could be made in order to arrive at conclusions.

Lesson 2 - a conceptualised approach.

A swing pendulum was designed as a teaching-learning aid. Learners were allowed to play with it for while. Activities that followed are outlined:

Activity 2.1.Pull and hold the pendulum at its maximum height. Identify the energy form it possesses at this height.

Activity 2.2.Let it return to its equilibrium position and hold it stationary at this position (minimum height).

Identify the energy form the pendulum has at this position.

Compare the two positions of the pendulum and indicate at which position it has

more energy while at rest.

Activity 2.3. Let the pendulum swing.

Identify and note the energy forms that are displayed during its swings.

Activity 2.4.From your knowledge and experience name any mechanism or apparatus from your environment that has similar features to this pendulum.

Lesson 3 and 4 - the principle of conservation of energy.

In lessons 3 and 4 the principle of conservation of energy was introduced. In the introductory phase learners were provided with dictionaries to look up the words "law" and "conservation" and instructed to write down their meanings. The purpose was to make learners aware of the meanings of these words in everyday language use as opposed to their meaning in science.

Lessons 5 and 6 - application stage.

A contextual project performed by groups of learners formed the application stage. In this stage learners were 
requested to conduct a case study from their immediate environment. In the case study the learners were requested to identify and recognize the application of the concept of energy and the principle of conservation of mechanical energy from their immediate environment.

Supporting evidence from their environment of learners' comprehension of the application of the concept of mechanical energy and its conservation was depicted by pictorial information brought forward as well as presentations

\section{Results of Questionnaires: Biographical Information}

The results of the biographical information requested from the learners are as follows:

$>$ Age: From their respective ages, an average age was calculated to determine the learners' level of cognitive development and compare it to the appropriate admission age for grade 10 as dictated by South African School Act's admission policy requirement (SASA, 1996:B-62). The average was found to be sixteen years for the target group (grade +6 years of age) and this complied with the policy as stated.

$>$ Gender: Gender was used to determine the composition of the class, i.e. how many girls and how many boys the class was composed of. The ratio of boys to girls was calculated and found to be approximately equal (19 boys and 18 girls). The ratio was 1:1.

Part 1 of the questionnaire (Conceptualised questions or item statements).

For Part 1 of the questionnaire, which was designed to test conceptual thinking and reasoning, learners still maintained a tendency of associating energy with living beings and objects in motion. This can be deduced from the results of questions 1.1, 1.2, 1.4 and 1.7 of the questionnaire. Responses for question 1.3, 1.6 and 1.7 shows that the majority of the learners did not yet comprehend the principle of conservation of energy and energy transfers depicted. For question 1.5 the responses were exceptionally good because the concept of force and work were dealt with before.

\subsubsection{Results and Discussion of Results}

The following responses of the learners were noted, analysed, evaluated and discussed. The pre-test results for Part 1 in the questionnaire of the survey study are communicated in the following table 1.

Table 1. Learners' responses to the conceptualised questions or item statements

Responses (out of37)

\begin{tabular}{|c|c|c|c|c|c|}
\hline Questions & Total & Yes & No & No response & \% of Correct responses \\
\hline 1.1 & 37 & 15 & 22 & 0 & 41 \\
\hline 1.2 & 37 & 33 & 4 & 0 & 89 \\
\hline 1.3 & 37 & 22 & 15 & 0 & 41 \\
\hline 1.4 & 37 & 9 & 27 & 1 & 24 \\
\hline 1.5 & 37 & 35 & 0 & 2 & 95 \\
\hline 1.6 & 37 & 27 & 10 & 0 & 27 \\
\hline 1.7 & 37 & 17 & 18 & 2 & 46 \\
\hline
\end{tabular}

Part 1 of the questionnaire: Reasons.

Item 1.1.(The stone inside the catapult).

John; 'Wo, the stone is rested inside the catapult"

Otshepeng: "No, the boy has energy, not the stone."

Lilian: 'Wo, the stone is at rest"

Lephahamiso: "No, because the stone doesn't that shows that it only gain energy when it is moving"

Alinah: "No, the boy is holding the stone inside the catapult. So it is not having energy"

John, Lilian, Lephahamiso and Alinah depicted association of energy with motion. The following ideas were picked up

from their responses:

John: "stone is rested."

Lilian: "stone is at rest."

Lephahamiso: "only gains energy when it is moving."

Alinah: "the boy is holding the stone inside the catapult"

The implications of the given responses show that learners think that when the object is at rest, it does not possess 
energy (John, Lilian, Alinah and Lephahamiso).

Item 1.2.(The launched stone)

John: "Yes, it has energy because it goes straight to the tin."

Otshepeng: "Yes, the stone is flying"

Lilian: "Yes, the stone is in the air and it is moving."

Lephahamiso; "Yes, because if the stone didn't have energy it would have fallen down while it was fired"

Alinah: "Yes, the stone will hit the tin with more energy."

Association of energy with motion was further displayed by the following key words from learners' responses to item 1.2:

John" "it goes straight to the tin"

Otshepeng: "the stone is flying"

Lilian: "the stone is in the air."

Lephahamiso: "if the stone didn't ' have energy it would have fallen down."

Alinah: "the stone will hit the tin"

Item 1.4.(The tin on top of the drum)

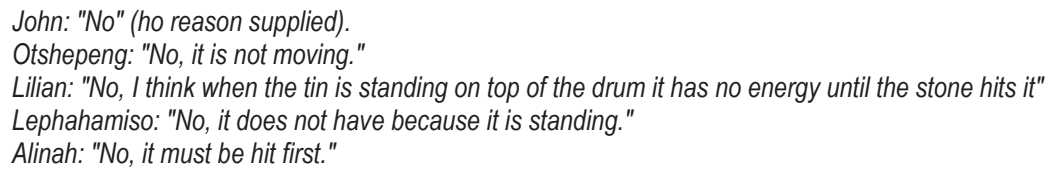

All learners responded by saying no and the reasons supplied by four learners (all except John) emphasized the association of energy with motion. The conception of gravitational potential energy due to the object's position above a reference level is not revealed in their responses.

Item 1.5.The concept of work

Item 2.5 was well responded to because the concept of force and work had been previously

dealt with. The following learners' responses for item 1.5 were picked up and recorded:

John: "Yes, the stone hit the tin and move it."

Otshepeng: "Yes, because when the stone hit the tin it moved."

Lilian: "Yes, when the tin falls, it shows force moves it"

Lephahamiso: "Yes, it was doing work on falling tin."

Alinah: "Yes, the tin moves and falls down."

Item 1.7.(The falling target)

John; "Yes, because it fall down and now it does have energy"

Otshepeng; "Yes, the energy is there because both the tin and the stone use energy to fall down."

Lilian: "Yes, the tin will fall down with the energy of the stone."

Lephahamiso; "Yes, because it is falling."

Alinah: "Yes" (no reason supplied).

The falling tin has energy because the word falling illustrates motion. This further indicates the association of the concept of energy with motion.

Association of energy with motion is depicted by responses for items 1.1, 1.2, 1.4 and 1.7 (John, Lilian, Alinah and Lephahamiso).

Item 1.3.(Energy changes and the principle of conservation of energy).

John: "Yes, the catapult created energy for the stone"

Otshepeng: "Yes, because the catapult has the string and that string gives and created energy for the stone"

Lilian: "Yes, because the catapult makes the stone moves"

Lephahamiso: "Yes, if there was no catapult, energy could not be created for the stone"

Alinah: "Yes, I think a person who pulls the catapult, because he/she uses lot and lot of strength, creates energy " 
Item 1.6. Energy changes and the principle of conservation of energy

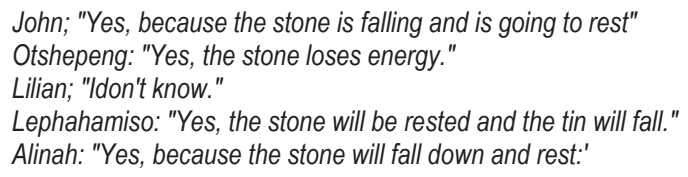

The concept of energy conservation and energy changes taking place in a system is not known as illustrated by the learners' answers for items 1.3 and 1.6. Key words used for the items were "created" and "lost ". Learners responded wrongly by saying energy was created by the catapult and was lost by the stone after hitting the tin.

The results for Part 1 of the questionnaire confirm the anthropomorphic and anthropocentric views held by learners with regard to the concept of energy as reported by Watt (1983:pp214-216) and Wesi (2003:p260). Learners also strongly associate energy with motion.

Table 1 summarizes the pre-test results by which one can arrive at assumptions and conclusions about the nature of learners' alternative conceptions regarding the concept of energy and the principle of conservation of mechanical energy. Secondly, these results also provide some ideas for the teacher to design his or her teaching and learning activities in a constructivist manner in order to enhance meaningful and effective teaching and learning of the concepts

Classroom observations during the intervention.

While doing the inquiry activities of the intervention, the learners responded to oral questions asked by the teacher as well as written questions on prepared work sheets.

Results for lesson 1.

From the activities carried out during the teaching-learning sequences designed to remedy learners' alternative conceptions about the concept of energy and the law of conservation of energy, the following were common responses from learners to guiding questions asked by the teacher:

Activity 1.1.Two balls (shot put and soccer ball) are rolled along a flat horizontal surface.

Guiding questions:

$>$ Do the rolling balls possess energy?

$>$ From the list of scientific definitions of terms, identify the energy form possessed by the rolling balls.

Common responses:

$>$ The balls have energy because they are moving.

$>$ The balls have energy of motion.

$>$ The balls have kinetic energy.

Activity 1.2.The raising act. Learners had to raise and hold steady a shot put ball at different levels (e.g. knee level, hip level and shoulder height).

Guiding questions:

$>$ What energy form does the ball possess through these heights?

$>$ At which height do you find it difficult to balance the shot put ball?

$>$ Compare the height through which the ball was raised to the work done to raise it and draw conclusions from your observations.

Common responses:

$>$ The ball possesses stored energy.

$>$ The energy is due to position.

$>$ Potential energy is seen as stored energy.

$>$ It is easy to lift the ball to knee level.

$>$ At shoulder height the ball seems to be heavier.

$>$ At shoulder height the ball is more difficult to balance as compared to knee level.

$>$ There is more potential energy at shoulder height.

The higher you raise the ball the more work is done.

Activity 1.3.The raising act as in activity 1.2 was repeated using two balls (soccer and shot put).

Guiding questions:

Which ball is the lighter of the two?

Which ball is easy to raise through the different heights mentioned? Justify your answer.

$>$ Which ball will hurt you most if it fell on your toe? Justify. 
Common responses:

$>$ The soccer ball is lighter than the other materials.

$>$ The soccer ball is easy to be raised through different heights because it is the lightest.

$>$ The shot put ball is difficult to be raised because it is heavier than the other materials.

$>$ The shot put ball will hurt most if it falls on your toe.

$>$ The shot put ball will break your toe because it has more mass.

$>$ The shot put ball has more stored energy and it will break your toe.

Analysis of the responses:

Analysis of the responses for activity 1.1 gives an indication that energy due to motion is always recognized. A reason could be that energy is associated with motion in everyday life .For activity 1.2 the concept of the gain in potential energy was gradually developed because learners were able to recognize that the ball was difficult to be raised to shoulder height as compared to knee level. For activity 1.3 learners were able to tell that an object with more mass possesses more stored energy. It is interesting to note the responses that refer to the consequences of having a high potential energy (e.g. "break your toe" and "hurt most"). This idea corresponds with the scientific concept of energy as the ability to do work. A conceptual understanding of the concept of work and the dependence of potential energy to the height and mass of an object, paves the way to formalization of the concepts.

Results for lesson 2.

The following responses were recorded during the activities:

Activity 2.1.The swinging pendulum.

Guiding questions:

$>$ The pendulum is at rest or equilibrium. What energy form does it possess?

$>$ The pendulum is pulled and held stationary at its maximum position. What energy form does it possess at this position?

Common responses:

$>$ If it is not moving it has potential energy.

$>$ It is high up there, therefore it has potential energy.

Activity 2.2.The swinging pendulum continued.

Guiding questions:

> Measure and compare the heights at which the pendulum is held stationary (at equilibrium and when pulled to its maximum position).

$>$ Identify the energy form possessed by the pendulum at these heights.

$>$ At which height does the pendulum possess more energy?

Common responses:

$>\mathrm{It}$ is held at rest so it has stored energy.

$>$ If it is not moving it has energy.

$>$ At the highest position there is more stored energy.

$>$ There is more energy at the top.

Activity 2.3.The swinging pendulum (energy changes within the system).

Guiding questions:

$>$ The pendulum is allowed to swing. Identify the energy forms displayed by the swinging pendulum.

Common responses:

$>$ When it is high up there it has potential energy.

$>$ However, when it swings it has energy of motion.

$>$ Swinging is shaking and moving so it possesses kinetic energy.

$>$ When it starts to swing, potential energy is converted to energy of motion.

Analysis of the responses:

The concept of energy changes (when the pendulum swings - energy of motion) taking place in a system was gradually introduced and learners were able to recognize that energy is the property of objects (living and non-living). This was evident from their responses that the object possessed stored or potential energy "when high up there".

The application of the concept of energy change was also readily observed from their immediate environment because the constructed swinging pendulum operated similarly to the children's swings on the village playground. While some learners correctly associated the gravitational potential energy of an object with its relative position to the earth, others only associated it with being at rest (or not moving). The idea that only and all stationary objects have potential energy is an alternative conception 
Contextualised project (Activity 3).

Guiding activities and questions:

$>$ From your immediate environment, observation and experience mention and name anything that operates in a similar fashion to the swinging pendulum.

$>$ Construct a model of this mechanism.

Common responses:

$>$ The children's swings on the village playground were readily and quickly mentioned.

$>$ Models of children's swings were constructed.

The following figures illustrate the reports submitted and the outcomes of the research study conducted by learners from their immediate environment regarding the concept of energy and the principle of conservation of mechanical energy. The presented pictures, discussions and reports that followed from this research study conducted by learners, show that learners were able to recognize and appreciate the application of the concept of energy and the principle of conservation of mechanical energy from their environment. Learners were given three pictures in,

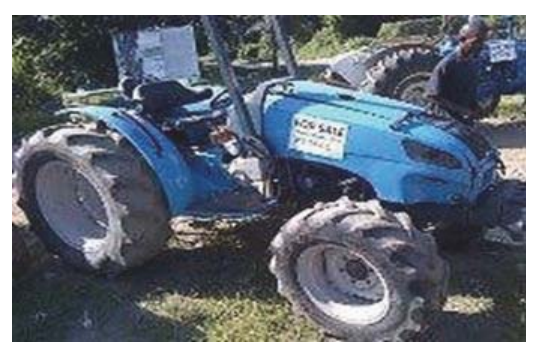

Figure 1: A tractor with a defective or malfunctioning battery or self-starter is always put on a sloping plane

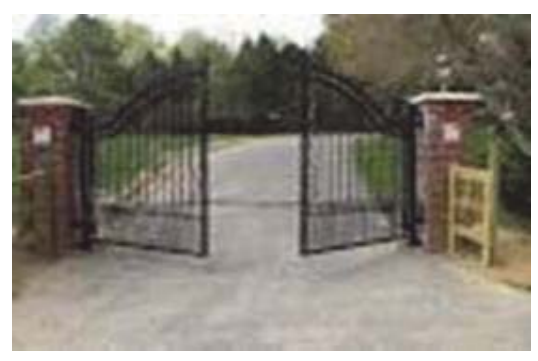

Figure 2: An automatic gate (open and closed) (a spring is attached to a gate for it to close on its own)

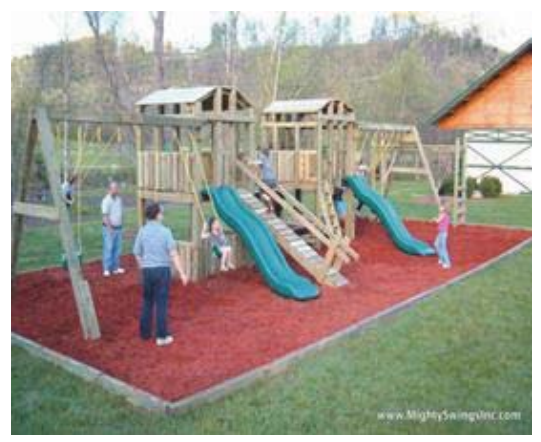

Figure 3: The playground (children's swings and sliding ramp). 
Interactive discussions through questioning as well as detailed evaluations of the reports and pictures presented were held with learners about the case study conducted by them. The following scientifically correct information from the learners was recorded:

Figure 1.

$>$ The tractor at the top of the incline possesses more potential energy than at the bottom of the incline.

$>$ When the tractor is allowed to roll down the incline, it gains kinetic energy (potential energy is transferred to kinetic energy as it moves down).

$>$ Halfway down the incline the tractor possesses an equal amount of kinetic energy and potential energy.

$>$ At the end of the incline, kinetic energy is more than potential energy.

Figure 2 .

A brief interactive discussion on the mechanism of the operation of the gate was given as follows:

Mechanism.

Parts and the method of construction of the gate were indicated and named by referring to the picture, i.e., a picture of the gate was displayed to the audience ( figure 2).

Operational details.

A model gate was presented and the operational principles explained as follows:

$>$ When opening the gate the spring stretches, thus the kinetic energy of the gate is transferred to the stretching spring (the stretching spring gains potential energy by doing work).

$>$ When releasing the gate, the potential energy of the spring is transferred to the gate. The gate then moves, closes down or returns to its original position.

Figure 3

The swings and sliding ramps are familiar and common on the playgrounds. Learners had vivid experiences of the swings and sliding ramps. The following experiences were relived in conjunction with the energy changes that took place during the swinging and sliding:

$>$ At the top of the sliding ramp potential energy is high and at the bottom of the sliding ramp kinetic energy is high.

$>$ At the highest point of the swing potential energy is high and at the lowest point kinetic energy is high.

$>$ During the downward motions, potential energy is converted to kinetic energy.

$>$ Energy is conserved.

In this regard it is evident that learners were able to identify the energy forms in the system, to recognize energy changes that took place in the system and name instances where the application of the principle of conservation of energy in mechanics was evident. The report of the learners on these contextualised situations reveals a progress in their attainment of the scientific conceptions of kinetic and potential energy, change in energy forms as well as the principle of conservation of mechanical energy.

Post-test Part 1 (conceptualised questions or item statements)

The post-test results for Part 1 in the questionnaire of the survey study done after the intervention was conducted are represented below in table 2 .

Table 2: Learners' responses to the conceptualised questions or item statements.

Responses (out of 37)

\begin{tabular}{|c|c|c|c|c|c|}
\hline Question & Total & Yes & No & No response & \% Of Correct responses \\
\hline 1.1 & 37 & 36 & 1 & 0 & 97 \\
\hline 1.2 & 37 & 35 & 2 & 0 & 94 \\
\hline 1.3 & 37 & 23 & 14 & 0 & 62 \\
\hline 1.4 & 37 & 31 & 6 & 0 & 83 \\
\hline 1.5 & 37 & 36 & 1 & 0 & 97 \\
\hline 1.6 & 37 & 10 & 27 & 0 & 73 \\
\hline 1.7 & 37 & 35 & 2 & 0 & 94 \\
\hline
\end{tabular}

The post-test results of Part 1 (table 2) in the questionnaire show significant improvement of the learners' conceptions about the concept of energy, energy conversions and the principle of conservation of mechanical energy. This follows from the learners' ability to identify and name kinds of energy in the system as well as their ability to notice and recognize energy transformation taking place within the system. 
The conceptual change that occurred due to the intervention is shown by learners' responses to questions and item statements in the questionnaire. The learners' usage of scientific words like potential and kinetic energy when responding to questions depicted this. In order to measure the effectiveness of the intervention in accomplishing conceptual change, the results were analysed statistically.

The normalized gains for each item statement or question and the total average normalized gains of Part 1 of the questionnaire are calculated. The calculations mentioned are outlined in table 3 for Part 1 of the questionnaire.

\section{Table 3: Calculated normalized gain for Part 1 of the questionnaire}

\begin{tabular}{|c|c|c|c|c|}
\hline Item & $\begin{array}{c}\text { Actual Gains Post- Pre- } \\
\text { Test } \%\end{array}$ & $\begin{array}{l}\text { Possible Gain 100\%- } \\
\text { Pre-Tset } \%\end{array}$ & $\begin{array}{l}\text { Normalized Gain Actual Gain\% } \\
\text { Possible Gain \% }\end{array}$ & $\begin{array}{l}\text { Normalized Gain } \\
\text { Expressed As \% }\end{array}$ \\
\hline 1.1 & $91 \%-41 \%=50 \%$ & $100 \%-41 \%=59 \%$ & $50 \% \div 59 \%=0.84$ & 84 \\
\hline 1.2 & $94 \%-89 \%=5 \%$ & $100 \%-89 \%=11 \%$ & $5 \% \div 11 \%=0.5$ & 50 \\
\hline 1.3 & $70 \%-41 \%=29 \%$ & $100 \%-41 \%=59 \%$ & $29 \% \div 55 \%=0.5$ & 50 \\
\hline 1.4 & $83 \%-24 \%=59 \%$ & $100 \%-24 \%=76 \%$ & $59 \% \div 76 \%=0.78$ & 78 \\
\hline 1.5 & $97 \%-95 \%=2 \%$ & $100 \%-95 \%=5 \%$ & $2 \% \div 5 \%=0.4$ & 40 \\
\hline 1.6 & $73 \%-27 \%=46 \%$ & $100 \%-27 \%=73 \%$ & $46 \% \div 73 \%=0.63$ & 63 \\
\hline 1.7 & $94 \%-.46 \%=48 \%$ & $100 \%-46 \%=54 \%$ & $48 \% \div 54 \%=0.89$ & 89 \\
\hline \multicolumn{3}{|c|}{ Total Average } & $4.54 \div 7=0.65$ & 65 \\
\hline
\end{tabular}

The total average normalized gain for Part 1 of the questionnaire is 0.65 and expressed as a percentage the normalized gain for Part 1 of the questionnaire is $65 \%$.

Expressed as a percentage the learners achieved a learning gain of $65 \%$. The high value of the average normalized gain (0.65) indicates that there was constructive conceptual change on the part of the learners regarding the concept of energy and the principle of conservation of mechanical energy (Hake, 2002:3). This normalized gain provides an indication of the effectiveness of the contemporary teaching-learning approaches as well as the use of context infused content used in the empirical study.

Analysis of the learners' responses for the activities designed and implemented during the intervention shows that learners were able to recognize and name different forms of energy (either kinetic, potential or both forms of energy). It also shows progress in the learners' understanding that potential energy can gradually be transferred to kinetic energy (and vice versa), while the total amount of mechanical energy remains constant in a closed system. Their application of the energy concept and the principle of conservation of energy from their immediate environment were observed in the project.

Learners' conceptual change was accomplished by the intervention. The anthropomorphic and anthropocentric views of learners regarding the concept of energy were gradually replaced by a more scientific meaning of the concepts. Learners' association of gravitational potential energy with all and only with stationary objects was changed to an understanding of the concept in terms of work done and the relative position above a reference level. The knowledge construction and conceptual changes that occurred during and after the intervention process is further confirmed by the statistical analysis of the pre-test and post-test results of the questionnaire. The large value of the average normalized learning gain (65\%) shows the effectiveness of the intervention in accomplishing conceptual change. The learners made good progress on their way towards an understanding of the scientific concepts relating to the principle of conservation of mechanical energy, although there is much room for further improvement. The research findings are categorized and analysed according to two stages namely, pre-test and post-test results. The analysis of the pre-test results of the empirical study conducted confirms that the learners used for the study had alternative conceptions regarding the concepts relating to the conservation of mechanical energy similar to those found in physics education research. Their alternative conceptions correspond with those given in the literature (e.g. Watt, 1983:p213; Wesi, 2003:p260), for example, association of energy with living things and motion, energy expenditure, energy as a fuel, etc. This observation might mean or could be generalized as a common trend of alternative conceptions found in or held by secondary school learners in South Africa regarding concepts relating to energy and conservation of mechanical energy.

\section{Conclusion}

The research study was conducted on the notion that alternative conceptions about the concept of energy and the principle of conservation of mechanical energy are commonly found among Grade 10 learners in South African schools 
(Wesi, 2003:p248). The research study also focused on a constructivist teaching-learning approach that can be used to reform, reconstruct or build upon learners' conceptions relating to the principle of conservation of mechanical energy (Trumper, 1991:p6; Trowbridge et al, 2002:p224; Scott et al, 1991:p7). It is on the basis of these notions that an action research methodology was used for the study.

The research findings are categorized and analysed according to two stages namely, pre-test and post-test results. The analysis of the pre-test results of the empirical study conducted confirms that the learners used for the study had alternative conceptions regarding the concepts relating to the conservation of mechanical energy similar to those found in physics education research. Their alternative conceptions correspond with those given in the literature (e.g. Watt, 1983:p213; Wesi, 2003:p260), for example, association of energy with living things and motion, energy expenditure, energy as a fuel, etc. This observation might mean or could be generalized as a common trend of alternative

The normalized learning gain of 0.65 obtained when the results of the questionnaire were processed is high, which indicates a high effectiveness of the intervention (Hake, 2002). However, the motivations given by the learners for their responses show that many of the learners hold intermediate concepts (Kaper\&Goedhart, 2002) such as the perception of potential energy as stored energy.

\section{References}

Boyes, E \&Stanisstreet, M.1990. Misunderstandings of "law " and " conservation": A study of pupils' meanings of these terms. School science review, 72(258): 51(Sep).

Bricker, P. (2005). Inquiry is essential to science learning. Connect, Synergy Learning. March-April.

Cutnell, DJ. \& Johnson, W. K. 2004.Physics.John Wiley and Sons, INC.

Department Of Education. 2003. National Curriculum statement grade 10-12: Physical sciences. South Africa.

Department Of Education. 2002. Revised National Curriculum statement grade R-9. National science gazette. South Africa.

Feldman, A. \&Minsterll, J. 2000.Action research as a research methodology for the study of the teaching and learning science.In A.E. Kelley, and R. Lesh (Eds).Handbook of research design in mathematics and science education.Mahwah. NJ. Earlbaum.

Friedl, E. A. 1991. Teaching science to children.An intergraded approach. McGrew Hill INC. USA.

Gunter, A. M; Estes, T. H. \&Schawb, J. 1991.Instruction.A model approach.Allyn and Bacon.

Hake, R.R. 2002. Interactive engagement v/s traditional methods: A six thousand-student survey of mechanics test data for introductory physics courses. Department of physics, Indiana University, Bloomington, Indiana 47405.

Hewitt, P.G.2002. Conceptual physics.9thedition. New York: Addison Wesley.

Kaper.W.H. \&Goedhart.M.J. 2002. 'Forms of energy' an intermediary language on the road to thermodynamics? Part 1.International Journal of Science Education, 24(1): 81-95.

Kask, K \&Rannikmae. 2006. Journal of Baltic Science Education, 9(1).

Kelly, P.D. \&Lesh, R.A. 2002. Hand Book of research design in mathematics and science education. Mahwah; NJ: Lawrence Erlbaun.

Kotz, J.C. \&Treichel, P. (Jr). 1996. Chemistry and Chemical reactivity. (3rdedition).Harcourt Brace College Publishers.

Leedy, P.D. \&Ormrod, J.E. 2001. Practical research: Planning and design.(7th Ed). Upper Saddle River, NJ: Merrill/ Prentice Hall.

Legge, K. A. \&Petrollito, J. 2003. The use of models in problems of energy conservation.American Journal of Physics, 721: 436-437.

Lemmer, M. 2008.Features and consequences of two school science curricula. Paper delivered at the GIREP conference, Nicosia, Ciprus, 18 - 22 August 2008.

Lemmer, M. \&Lemmer, T.N. 2005.Contextualisation as a didactical approach to physics education. (In: Grayson, D.J. (Ed) What Physics should we teach? Proceedings of the International Physics Education Conference, Durban, 5-8 July 2004.) p 212 - 218.

Lemmer, M \&Lemmer, T.N. 2008.A hypothesis of the learning process to act as basis for science curriculum development. Paper delivered at the GIREP conference, Nicosia, Ciprus, 18 -22 August 2008.

Mann, M, Treagust, D. 2013. Students' conceptions about energy and the human body. Science Educational International, 21(3):144159.

Mcbride, W. J.; Bhatti. L. M; Hannan, A M. \& Feinberg, M. 2004. Using an inquiry approach to teach science to secondary school science teachers. Physics Education, 39(5): 434-439

Meheut, M. \&Psillos, D. 2004. Teaching - Learning science. Aims and tools for science education research. International Journal of Science Education, 26(5)) 515-535.

Meltzer, D. E. 2002. The relationship between mathematics preparation and conceptual learning in physics.A possible 'hidden variable' in diagnostic pre-test scores.American Journal of Physics, 70(12): 1259-1268.

Niewoudt, H.D. \& Beckley, W. 2008. Participative teaching. (In: Jacobs, M. Vakalisa, N. \& Gawe, N. Teaching-learning dynamics: A participative approach to OBE. 3rd Edition. Sandton: Heinemann Publishers) p 311 - 349.

Ogunniyi, M. B. \&Taale, K. D. 2004. Relative effects of a remedial instruction on grade seven learners' conceptions of heat, magnetism and electricity.African Journal of Research in SMT education, 8(1): 77-87.

Prince, M \& Margot V. 2012. Using inquiry based activities to repair students misconceptions related to Heat, Energy and Tempertaure.Department Of Chemical Engineering. Bucknell University.

Prince, M \& Felder , R, 2007.Inductive teaching and learning methods: Definitions, comparisons, and research bases. Journal of 
Engineering Education, 95(2):123-138

Rankhumise, M.P. \&Lemmer, M. 2008. Effective teaching of energy in grade 10 mechanics: A case study. Accepted for publication in the Proceedings of the $16^{\text {th }}$ annual conference of SAARMSTE, 14-18 January, Maseru, Lesotho.

Redish, E. F. 2003. Teaching physics with the physics suite. John Wiley and Sons INC. University of Maryland. USA.

Roth, W. M. \&Mcginn, K. M. 1998.Knowing, research, and reporting science education.Lessons from science and technology. Journal of Research in Science Education, 35(2): 213-235.

Scholtz, Z. \&Amuson, R. 2004.Investigating science teachers' response to curriculum innovation.African Journal in SMT Educational): 41-52.

Scott, P. H.; Asoko, H. M. \& Driver, R. H. 1991.Teaching for conceptual change.A review of strategies.http://www.phvsics.ohiostate.edu/ jossem/ICPE/C5.htm.. Date of access. 05 June 2006.

Sexl, U. R. 1981. Understanding energy as a conserved quantity.Journal of Science Education, 3: 291-301.

Trowbridge, L. W.; Bybee, R. W. \& Powell, J.C. 2000.Teaching Secondary School Science.Strategies for developing scientific literacy.(7thedition).Merrill, An imprint of Prentice Hall.Upper Saddle River. NJ. Columbus, Ohio.USA.

Trumper, R.O. 1991.Being Constructive.An alternative approach to the teaching of energy concept. Part two. International journal of Science Education, 13: 1-10.

Trumper, R.O. 1990.Energy and Constructive way of teaching.Physics Education, 25: 208-212.

Wesi, P.R. 2003. Conceptual difficulties associated with the energy concept. Thesis submitted in the school of science, mathematics and technology education. Potchefstroom University.Potchefstroom.RSA.

Watt, M.D. 1983. Some alternative views of energy. Physics Education, 18: 213-216.

Zain, A.D.MD. \& SULAIMAN, F. 1998. Physics students' conceptions of energy and technological development in energy.Renewable Energy, 14: 415-419. 